METHODOLOGIC ISSUES

\title{
Design and implementation of injury prevention curricula for elementary schools: lessons learned
}

\author{
R Azeredo, S Stephens-Stidham
}

Injury Prevention 2003;9:274-278

\begin{abstract}
Objectives: Project objectives were to: (1) design and produce an easy-to-use, replicable comprehensive injury prevention curriculum for elementary schools; (2) pilot the program to determine instructors' ease in teaching the material and its usefulness in enhancing student knowledge and behavior change; (3) present material in subject-integrated, grade-specific lessons that would meet state and national student learning objectives; and (4) submit and obtain adoption of the curriculum by the State Department of Education.

Methods: A pilot program was developed, implemented, and evaluated in six intervention and six control schools. The curriculum was revised and implemented in five other schools and finalized according to evaluation results and teachers' and parents' suggestions. Community resources such as police, fire, and county health departments participated in program implementation. Results: The program showed a significant increase from $21 \%$ to $36 \%$ in seatbelt use during the school year in program schools compared with a $1 \%$ decrease in control schools. Bicycle helmet use increased from $0 \%$ to $10 \%$ in the program schools. Pre-test and post-test results showed significant differences in student knowledge, attitudes, and behaviors within the program schools, and in comparing the program and control schools. On a Likert scale of 1 (poor) to 7 (excellent), teachers rated lesson content, exercises, and the usefulness of materials and resources as 5.8,5.5, and 5.4, respectively. Evaluations for the revised curricula ranged from 5.7 to 6.2 .

Conclusions: The favorable evaluation results resulted in the adoption of the curriculum as a state textbook, and widespread teaching of the curriculum. The product is appropriate and efficacious in these elementary schools and their communities.
\end{abstract}

See end of article for authors' affiliations

A mong children 5-14 years of age, injuries account for $56 \%$ of all deaths. The highest rates of injury mortality, morbidity, and consequent disability in children relate to traumatic brain injury (TBI), spinal cord injury (SCI), burns and submersions. ${ }^{12}$ In Oklahoma, statewide surveillance data collected since 1988 on fatal and hospitalized cases of burns, submersions, and SCI and since 1992 on TBI show that the 5-14 year age group incurred 667 burns (average annual rate 9.6 per 100000 population), 226 submersions (rate 3.0), 296 SCIs (rate 1.1), and 2876 TBIs (rate 58.2). The leading causes of TBI in this age group were motor vehicle crashes $(21 \%)$, falls $(23 \%)$, bicycle related events (16\%) and sports (14\%).

Although age, race, education, and income are cited as factors affecting behavior, individual perceptions of risk taking greatly influence actions and safety practices. ${ }^{3}$ Previous attempts to prevent injuries through educational methods have been disappointing but it is reasonable to assume that on-going school based education is more likely to be effective than single exposure presentations. Teaching safety habits to elementary school aged children may also have effects that extend to older age groups. This report examines the development and effectiveness of a curriculum based on these principles and assumptions.

\section{METHODS}

A comprehensive elementary school injury prevention curriculum was developed, piloted, and evaluated by the Injury Prevention Service of the Oklahoma State Department of Health.

\section{Design and development of program}

The program was first designed to include one week, nine week, and 18 week curricula, focusing on safety belts, bicycle

Abbreviations: $\mathrm{SCl}$, spinal cord injury; $\mathrm{TBI}$, traumatic brain injury

helmets, and smoke alarms. The intent was to compare differences in students' knowledge, attitudes, and behavior before and after the program for each period of exposure, and contrast the results of the three programs. Northeastern Oklahoma was selected because reported safety belt use rate was low (30.4\% compared with the state rate of $37 \%$ ). Muskogee, population 39000 , was selected because schools included minority groups and were both urban and rural.

While negotiating with Muskogee to implement the program, teachers suggested the program be extended and that schools have the opportunity to teach the curriculum over an 18 week or 27 week period. One private and five public schools agreed to implement the program whereas a similar number of public and private schools served as controls providing safety belt observations and pre-tests and post-tests. Student characteristics, class size, and abilities of teachers did not differ between program and control schools. During program development, it was decided to include all injuries within a comprehensive curriculum. The curricula were written and implemented during the 1992-93 school year.

\section{Theoretical basis}

Conceptually, the curriculum was derived from epidemiologic evidence and injury prevention methods. It was based on applied learning, behavioral and socialization theories which posit that repeated, spaced messages using interrelated themes and varied modes of delivery best increase understanding, knowledge retention, and sustained behavior change. ${ }^{4-8}$ Strategies to inspire creativity and learning included mathematical and science problems, creative writing, role 


\begin{tabular}{|c|c|c|c|c|c|}
\hline 6 Program schools & Pre-program & 18 weeks & 27 weeks & Post-program & quasiexperimental time series design \\
\hline Safety belt observations & $O_{1 A}$ & $X_{S}$ & $--X_{F}$ & $\mathrm{O}_{3 \mathrm{~A}}$ & $\begin{array}{l}\text { of program and control schools. } \\
\text { Design notation modified from Cook }\end{array}$ \\
\hline Pre-test and post-test & $\mathrm{O}_{1 \mathrm{~B}}$ & $X_{S}$ & $--X_{F}$ & $\mathrm{O}_{2 \mathrm{~B}}$ & \\
\hline \multicolumn{5}{|l|}{6 Control schools } & measures from a single group: $S$, \\
\hline Safety belt observations & $\mathrm{O}_{1 \mathrm{~A}}$ & $\mathrm{O}_{2 \mathrm{~A}}$ & & $\mathrm{O}_{3 \mathrm{~A}}$ & $\begin{array}{l}\text { start; } F \text {, finish. I wo groups (program } \\
\text { and control) are illustrated. }\end{array}$ \\
\hline Pre-test and post-test & $\mathrm{O}_{1 \mathrm{~B}}$ & & & $\mathrm{O}_{2 \mathrm{~B}}$ & \\
\hline
\end{tabular}

playing, stories, visual enforcement, and hands-on examples. ${ }^{90}$ Injury prevention messages were both overt and subtle.

\section{Curriculum}

The curriculum was designed to increase knowledge, skills, and awareness of injuries, risk factors, causes, consequences, and protective measures. It attempted to instill the belief that children have the capability to develop safety habits.

\section{Muskogee pilot program}

The program was piloted to evaluate and improve the curricula with respect to quality, effectiveness, and replicability.

Main elements included: (1) 18 and 27 lesson curricula for grades kindergarten to $1,2-3,4-5$ with complete lesson plans; (2) a smoke alarm giveaway project involving schools and fire department; (3) school bicycle fairs with helmet giveaways; (4) safety penpal letters involving third grade students in program schools and four schools out-of-state; (5) letters to parents; and, (6) injury prevention talks at parent-teacher meetings.

\section{Seatbelt use}

Classroom graphs were used to record students' self reported safety belt use daily. Belt use was then summarized for each class and each school monthly and recorded on a 48 by 36 inch thermometer "SafeStat" displayed at the school entrance to illustrate belt use during the program. The words "safety belt", written by parents in several languages, were highlighted.

\section{Smoke alarm giveaway}

All families in the control schools had the opportunity to have a smoke alarm installed by firefighters. When a fire broke out in a home where an alarm had been installed and the family was alerted in time to escape, the local newspaper credited the program.

\section{Bicycle helmet giveaways}

Bicycle fairs were held during assemblies with a "safety talk" given by a staff member, principal, or firefighter. Helmets were fitted and given to children whose parents completed an application.

\section{Safety penpal letters}

Four schools in Massachusetts and New York agreed to have students be penpals with those in program schools. Oklahoma students wrote letters about injury prevention and safety habits. Packets of sealed letters, including a postcard map of Oklahoma, were sent, and schools out-of-state sent letters back, many with small gifts.

\section{Lessons}

The 30-45 minute lessons for basic subjects included safety messages imbedded in the exercises and activities. To illustrate, fourth grade students' social studies lessons involved learning Oklahoma's safety belt use laws, reviewing key provisions of all states' belt laws, writing letters to legislators, and how to have a safety belt law passed in Oklahoma.
The brain and spinal cord injury lesson involved learning anatomical descriptions related to risk factors, sentence completion about the brain, spine, and safety habits, doing arithmetic problems involving safe water depth, and calculating students' use of seatbelts. Injury protection, choice, and the value of good safety habits were central themes.

\section{Classroom supports}

Photocopied sets of all lesson materials were provided for teachers and safety folders for students. Smoke alarms, safety belts, bicycle helmets, Muskogee and Oklahoma maps, and safety pamphlets were placed in classrooms, and videos and audiocassettes in school libraries.

\section{Measuring change in knowledge, attitudes, and behavior}

Observations of safety belt use were scheduled before, during, and two weeks after the program. (Although observations three months after the program were planned, principals reported that many students had emigrated or immigrated resulting in student population change, making such comparisons meaningless.) Bicycle helmet observations were conducted in program schools before and after the program. Written tests were given before and after the program to determine the utility and appropriateness of items in assessing changes in knowledge, attitudes, and behavior and self reported behavior, and to make comparisons between the two groups. The design illustrating program implementation, tests, and seatbelt observations is shown in fig $1 .{ }^{11}$ Self reported safety belt use was an additional measure.

\section{RESULTS}

\section{Safety belt observations}

A majority of students rode with parents; others walked, and about $3 \%$ rode bicycles to and from school. Five percent of children in the private and $10 \%-12 \%$ in public schools used busses. Belt use was counted for front seat occupants only. A total of 4750 observations on students arriving at school in personal vehicles and sitting in front passenger positions were completed. At the time of implementation, airbags were not in common use and recommendations had not been made for children younger than 13 to sit in the back seat.

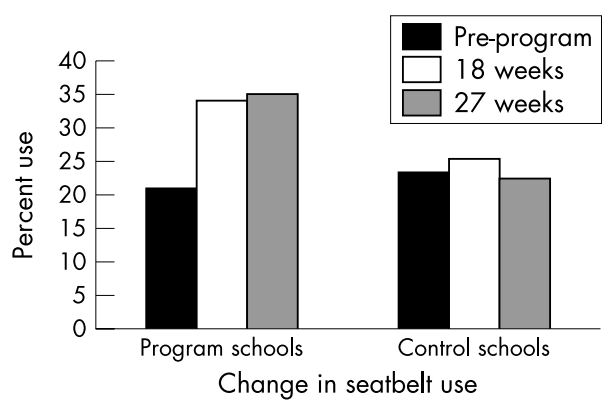

Figure 2 Observed passenger safety belt use before, during, and after intervention in program and control schools. 
Table 1 Significant differences in students' pre-tests and post-tests for knowledge, attitude, and behavior in program schools

\begin{tabular}{lrr}
\hline Characteristic & \multicolumn{1}{l}{$\chi^{2}$} & $p$ Value \\
\hline Grades kindergarten-1 & & \\
Use of seatbelt always (B) & 4.2 & 0.04 \\
Emergency telephone numbers (K) & 6.3 & 0.01 \\
Three good safety habits (K) & 6.6 & 0.02 \\
Train warnings (K) & 13.4 & $<0.01$ \\
Good swimming habits (K) & 22.0 & $<0.01$ \\
Fire safety rules (K) & 13.8 & $<0.01$ \\
Bicycle safety rules (K) & 21.4 & $<0.01$ \\
Diving safety (K) & 22.8 & $<0.01$ \\
Creative problem solving (conflict & 26.6 & $<0.01$ \\
resolution) (B) & & \\
Grades 2-5 & 8.6 & $<0.01$ \\
Response in emergencies (K) & 11.2 & $<0.01$ \\
Pedestrian rules (K) & 24.5 & $<0.01$ \\
Bicycle safety (K) & 5.4 & $<0.01$ \\
Water safety rules (K) & 22.6 & $<0.01$ \\
Helmets as head protection (K) & 13.4 & $<0.01$ \\
Gun safety rules (K) & 22.0 & $<0.01$ \\
Creative problem solving (conflict & & \\
resolution) (B) & 12.4 & $<0.01$ \\
Diving/swimming safety (B) & 48.0 & $<0.01$ \\
Fire safety (K) & 6.8 & 0.03 \\
Importance of safety belts (A) & & \\
\hline A, attitude; B, behavior; K, knowledge. & & \\
\hline
\end{tabular}

Program schools showed a significant increase of $21 \%$ to $36 \%$ in belt use compared with a $1 \%$ decrease in control schools (fig 2). Student reported belt use in program schools, obtained from class graphs and "SafeStat" measures, increased from $42 \%$ to $65 \%$, indicating that self reported use was twice that of observed use. Driver belt use showed an increase of $2 \%$ in program schools compared to no increase in control schools.

Bicycle helmet observations conducted before and after in program schools showed that helmet use increased from $0 \%$ to $10 \%$.

\section{Pre-tests and post-tests}

Approximately 6300 pre-tests and post-tests were completed by students in the 12 schools. Tests were composed of 14 item activity and simple written questions for kindergarten to 1 , and 20 item true/false and multiple choice questions for grades $2-3$ and $4-5$. Three questions elicited information concerning type of family vehicle and where the student usually sat. Aggregate data were analyzed for grades kindergarten to $1,2-3$, and $4-5$ levels by program versus control school status. Significant differences were found in students' knowledge, attitudes, and behavior before and after the program in program schools (table 1). Comparison of students' post-tests showed significant differences in knowledge, attitudes, and behavior between the program and control schools (table 2).

Certificates of recognition were given to program schools and results presented at the annual school board/City Council meeting. Injury prevention and safety rules similar to those outlined in the program were included in requirements drafted by the School Improvement Division of the Oklahoma Department of Education.

\section{DISCUSSION}

Knowledge and experience in injury epidemiology and prevention, behavior change strategies, and educational psychology and research were used in writing this curriculum. Literature reviews of injury prevention programs, review of student textbooks for all subjects (kindergarten to grade 6), and study of testing manuals were completed to help create appropriate lesson exercises.
Table 2 Significant differences in students' post-tests for knowledge, attitude, and behavior between program and control schools

\begin{tabular}{lrr}
\hline Characteristic & \multicolumn{1}{c}{$\chi^{2}$} & $\mathrm{p}$ Value \\
\hline Grades kindergarten-1 & 5.2 & 0.04 \\
Use of safety belt (B) & 65.1 & $<0.01$ \\
Emergency contact (K) & 22.6 & $<0.01$ \\
Good safety habits (K) & 15.3 & $<0.01$ \\
Reason for using safety habits (A) & 4.3 & 0.03 \\
Bicycle helmets as protection (B) & 13.0 & $<0.01$ \\
Intersection/stop signs (K) & 13.4 & $<0.01$ \\
Train warnings (K) & 17.6 & $<0.01$ \\
Good swimming habits (K) & 16.9 & $<0.01$ \\
Intersection/stop signs (K) & 29.0 & $<0.01$ \\
Creative problem solving (conflict & & \\
resolution) (B) & & \\
Grades 2-5 & 8.6 & $<0.01$ \\
How to handle emergencies (K) & 9.1 & $<0.01$ \\
Pedestrian rules (K) & 31.7 & $<0.01$ \\
Bicycle rules (K) & 9.9 & $<0.01$ \\
Water safety rules (K) & 11.4 & $<0.01$ \\
Gun safety rules (K) & 24.7 & $<0.01$ \\
Helmets as protection (B) & 5.7 & 0.04 \\
Home fire safety (K) & 19.6 & $<0.01$ \\
Creative problem solving (conflict & & \\
resolution) (B) & 7.1 & $<0.01$ \\
Diving safety (A) & 18.5 & $<0.01$ \\
Importance of safety belts (A) & & \\
\hline A, attitude; B, behavior; K, knowledge. & & \\
\hline
\end{tabular}

When the program was developed in 1992, the only safety curriculum available was one written by the Oklahoma Department of Education addressing bus and intersection safety. ${ }^{12}$ In 1988, apparently the first program outlining methods for teaching healthy living in an elementary school system was described. ${ }^{13}$ Healthy People 2010 cites the continued goal to teach health and safety behaviors in elementary schools. ${ }^{14}$

Curricula and programs targeting school children proliferated during the 1990s. ${ }^{15}{ }^{16}$ In 1995, Think First for Kids: The Brain and Spinal Cord Injury Prevention Curriculum for Teachers, was developed by the author of the Oklahoma injury prevention curriculum. ${ }^{17}$ In 1998, Risk Watch was published addressing eight risk areas for grades pre-kindergarten to kindergarten, grades $1-2,3-4,5-6$, and $7-8 .^{18}$

\section{Revision and current status of curriculum}

Based upon the effectiveness of the pilot program and suggestions from teachers, principals and parents, the curriculum was rewritten to be grade-specific (kindergarten to 5) and included three additional injury topics, state laws, and resources. The additional lessons included "Creative Problem Solving", "Safety Around Firearms", and "Injuries to the Brain and Spinal Cord". The revised curricula were implemented in three rural schools in 1993-94; further refined curricula were implemented in two Oklahoma City urban schools in 1994-95. The final curriculum incorporated suggestions from 154 teachers from six state and three out-of-state school districts, principals, state educators, national student testing consultants, and guidance specialists. Curriculum content and safety themes are shown in boxes 1 and 2 . A descriptive brochure was developed and the curricula presented at 30 teacher meetings statewide. The process of obtaining approval and adoption as a school text in 1997 involved applying for an ISBN number and giving multiple presentations to schools, regional meetings, and the Textbook Committee. The curriculum is now being taught in more than 650 schools in Oklahoma and at 32 schools in 14 other states.

\section{Program evaluation}

Formative, process, and impact evaluation were conducted for the pilot program through continuous contact with teachers. 


\section{Box 1: Curriculum content}

1. Table of contents

2. Rationale and goal of curriculum.

3. Teachers' summary guide to the curriculum.

4. Definition of terms used in the curriculum.

5. Twenty five lessons that include:

- Lesson plan with objectives, duration, materials, and focus activities.

- Reference to specific national testing objectives and PASS requirements met in the lesson.

- Injury related information and fact sheets for teachers.

- Injury prevention messages within subject related exercises.

- Activities.

- Letters to parents.

- Lesson specific tests and surveys.

6. Oklahoma laws related to car safety restraint systems,

intersections, pedestrians, and firearms in schools.

7. Resource list of audio and video tapes for lessons.

8. Suggested additional activities with related materials.

9. Lesson-subject exercises answer key.

10. Separate indexes with references to lessons for:

- Oklahoma PASS requirements.

- National student testing objectives.

- Safety themes.

11. Set of reproducible exercise and activity sheets.

12. Pre-tests and post-tests.

Formative evaluation involved the receptiveness of teacher training, negotiation in establishing protocols, and the quality of teachers' suggestions for incorporating the curriculum within their lesson plans. Process evaluation included feedback from, and observations of individual teachers' work at weekly meetings and with all staff where expectations and ways to ease implementation were discussed. Impact evaluation included the results of safety belt and bicycle helmet use observations, student reported belt use, comparisons of observed versus self reported belt use, comparisons of pre-tests and post-tests in program schools, comparison of belt use and pre-tests and post-tests between the two groups, review of school coordinators' recorded notes, and teachers' and principals' written evaluations.

Seventy eight principals and teachers in program schools (83\%) completed evaluations using a Likert scale of 1 (poor) to 7 (excellent). Main items rated were lesson content (mean 5.8 ), activities (mean 5.5), and the usefulness of materials and resources (mean 5.4).

Program effectiveness was also shown by the response of the community. Firefighters installed 250 alarms in students homes and law officers conducted seatbelt practice for all students in grades kindergarten to 3. Over 1300 bicycle helmets were distributed at helmet fairs at school assemblies. Smoke alarm and bicycle helmet giveaways invoked enthusiastic participation among students and teachers. Quality of delivery varied within and among schools; estimation of teachers implementation of all program elements ranged from $75 \%$ to $100 \%$. Students of teachers in schools with greater demonstrated commitment had higher post-test scores. Implementation of the revised curricula was less rigorous; teachers were requested to teach at least eight lessons with diverse injury prevention messages. Informal process evaluation included weekly communications and feedback from teachers concerning needs or problems with implementation. Free bicycle helmets were given to children whose parents completed the applications. Teachers reported students' performance on tests informally but no evaluative measures were taken.

Outcome evaluation of injury prevention programs is rarely accomplished because of the difficulty in relating changes in injury rates only to the program. The reviews by Towner et al of the international literature on child injury prevention and outcome of interventions found that educational campaigns

\section{Box 2: Safety themes in curriculum}

- Anatomy of brain and spine.

- Safety belt use across cultures.

- Legislative process/writing to legislators.

- Brain and spinal cord injuries.

- Helmet use.

- Bicycle safety.

- Car safety.

- Creative problem solving.

- Emergencies/getting help.

- First aid.

- Home safety.

- Other vehicle/bus and traffic safety.

- Pedestrian safety.

- Safety around guns.

- Smoke alarms and fire safety.

- Traffic signs and signals.

- Intersections and railroad crossings.

- Water safety.

and legislative change can achieve some positive effects on behavior but found little evidence of lower injury rates. ${ }^{190}$ Hodge noted that the importance of injury prevention evaluation is to identify effective prevention measures and to shift resources to what "works". ${ }^{21}$ The Oklahoma injury prevention program was successful in increasing knowledge, attitudes, and behavior, and safety belt and helmet use among students.

Program success was largely determined by the lesson content and teaching methods. How long children will remember, use, and act upon whatever information was retained in their long term memory is unknown. Observed learning, through modeling can teach new behaviors and values. ${ }^{22}$ Motivation, and the ability to concentrate and to process information also explain learning. ${ }^{23}$ Teachers have the opportunity to influence children second only to parents. If injury safety lessons are taught each year, students will have continued exposure and, possibly, sustained behavior. Many variables interrelate to affect behavior such as teacher interest, parents, the home environment, and students' ability to relate messages to their daily living.

\section{Limitations}

The main limitation of the pilot program was the scope and detail of activities external to curriculum lessons. Considerable teacher time was applied to the application process for smoke alarms and bicycle helmet giveaways, and to daily recording of student safety belt use. The plain appearance of the curricula, compared with newly available and colorful materials, was also a limitation. Also, inclusion of "Oklahoma" in the curriculum title at the request of teachers limits out-ofstate marketability.

The difference in observed belt use among program schools may have been attributable to teachers' interest, the school environment, or weather conditions; these factors were not evaluated.

\section{IMPLICATIONS FOR PREVENTION}

School-integrated injury prevention curricula/programs should remain a principal strategy for long term instruction and behavior change. The materials are usually well written and developmentally and grade appropriate, and children experience several years of exposure. Safety behavior may be sustained if ingrained as a normal part of life, such as seatbelt use in states with education, legislation, and enforcement. Costs of materials and implementation should be minimal so as to ensure availability to all populations.

\section{ACKNOWLEDGEMENTS}

We wish to thank Mike Garde, Director of Curriculum Development and Student Services of Muskogee School District \#120 for his 


\section{Key points}

- A comprehensive elementary school injury prevention curriculum/program was implemented in Muskogee to increase children's knowledge of injury and use of safety habits.

- Comparative results showed a significant increase of $15 \%$ in observed belt use in program schools compared to a $1 \%$ decrease in control schools, an increase from $0 \%$ to $10 \%$ in bicycle helmet use before and after the program in program schools, and significant differences in knowledge, attitudes, and behavior between the program and control schools.

- Although there are no clear indications if student learning has taken place, it may be assumed when students have increased knowledge of a subject or when they behave in ways they did not before instruction.

- Children 5-14 years are more likely than adolescents and adults to learn and use new safety habits because of their desire to emulate positive behaviors.

- Repeated, spaced, and interrelated safety messages within subject material are more likely to be assimilated than single exposures, and are an effective teaching method.

- Formative, process, and impact evaluation should be an integral part of all injury programs and research.

suggestions; Dorothea Baltes, for reviewing the curricula; and Sue Mallonee, Chief, Injury Prevention Service, Oklahoma State Department of Health, who edited the final curriculum. We also thank the principals and teachers of all the schools involved, the Muskogee County Health Departments, and the Injury Prevention Service staff who did the observations.

Supported in part by grant \# U59/CCU607004-02, Centers for Disease Prevention and Control.

Authors' affiliations

R Azeredo, S Stephens-Stidham, Injury Prevention Service, Oklahoma State Department of Health

\section{REFERENCES}

1 Public Health Service. Promoting health/preventing disease: year 2000 objectives for the nation. Washington, DC: Department of Health and Human Services, 1989
2 Institute of Medicine. Disability in America: toward a national agenda for prevention. Washington, DC: National Academic Press, 1991.

3 Anonymous. Impact of adult safety belt use on restraint use among children $<11$ years of age - selected states, 1988 and 1989. MMWR Morb Mortal Wkly Rep 1993;42(14):275-8.

4 Bigge ML. Learning theories for teachers. 3rd Ed. New York, NY: Harper and Row, 1976.

5 Le Francois GR. Psychological theories and human learning. 2nd Ed. Monterey, CA: Brooks Cole, 1982: 233-57.

6 Perruclet $\mathbf{P}$. The effect of spaced practice on explicit and implicit memory. Br J Psychol 1989;80:1 13-30.

7 Baddeley AD. Reading and working memory. Visible-Language 1984;18:311-22

8 Baddeley AD. The psychology of memory. New York: Basic Books, 1976.

9 Woolfolk AE. Educational psychology. 3rd Ed. New Jersey: Prentice-Hall, 1987.

10 Borich GD. Effective teaching methods. 4th Ed. Upper Saddle River, NJ: Merril-Prentice Hall, 2000

11 Cook TD, Campbell DT. Quasi-experimental design and analysis. Boston, MA: Houghton Mifflin, 1979.

12 Oklahoma Department of Education. Scottie the scarecrow. Oklahama City: Oklahoma Department of Education, 1987.

13 Carleton RA, Dwyer J, Finberg L, et al. Report of the Expert Panel on Population Strategies for Blood Cholesterol Reduction. Circulation 1991:83:2154-232.

14 US Department of Health and Human Services. Healthy people 2010. 2nd Ed. With understanding and improving health and objectives for improving health. 2 Vols. Washington, DC: US Government Printing Office, November 2000

15 Richards JS, Hendricks C, Roberts M. Prevention of spinal cord injury: an elementary education approach. J Pediatr Psychol 1991;16:595609

16 Baylor College of Medicine. Brainlink project. Houston, TX: Baylor College of Medicine, 1993

17 American Neurosurgical Association. Think first for kids. Rollingwood IL: American Neurosurgical Association, 1995.

18 National Fire Protection Association and Lowe's Home Safety Council. Risk watch: a comprehensive curriculum for children in preschool through grade 8. Quincy, MA: National Fire Protection Association and Lowe's Home Safety Council, 1998.

19 Towner E, Dowswell T, Jarvis S. Updating the evidence. A systematic review of what works in preventing childhood unintentional injuries: part 1. Inj Prev 2001;7:161-4.

20 Towner E, Dowswell T, Jarvis S. Updating the evidence. A systematic review of what works in preventing childhood unintentional injuries: part 2. Inj Prev 2001;7:249-53.

21 Hodge M. Evaluating injury prevention interventions. Inj Prev 2002;8:8-9.

22 Bandura A. Social foundations of thought and action: a social cognitive theory. Englewood Cliffs, NJ: Prentice Hall, 1984.

23 Chronbach LJ. Educational psychology. 3rd Ed. Harcourt Brace Jovanovich, 1977: 449 